\title{
Plasmacytoid Lymphocytes: A Diagnostic clue to Dengue Infection
}

\author{
Dr. Kishore Khatri*, Dr. Anil Rajani**, Dr. A R Kalla\#\# \\ ${ }^{1}$ Assistant professor, Department of pathology, Dr S N Medical College, Jodhpur \\ ${ }^{2}$ Medical Officer, Department of pathology, Dr S N Medical College, Jodhpur \\ ${ }^{3}$ Professor \& Head, Department of pathology, Dr S N Medical College, Jodhpur
}

\begin{abstract}
Introduction: Dengue fever is the most common arboviral disease in world and present cyclically in tropical and subtropical regions. The four serotypes of dengue virus 1,2,3,4 come under subgroup of Flavivirus( Group B arboviruses). Dengue is now becoming a commonest vector borne infection in India. Clinical diagnosis can be difficult as its presenting signs and symptoms are easily confused with malaria, typhoid and other non specific viral infections. In developing countries like India where huge population is being endemic and resources are limited, early and effective assessment of CBC and PBF can be very helpful in patient management. Material and method: A cross sectional study was carried out on a series of patients presenting with High grade fever, bodyache and lethargy. CBC and $\mathrm{PBF}$ were first performed for every patient. Those having thrombocytopenia and atypical plamacytoid lymphocytes were further analysed by Dengue rapid card test for NS1 Ag and IgM antibody. Results: Out of 150 patients, 50 were found dengue positive by Either Ns1 Ag or IgM antibody. All 50 patients showed atypical plasmacytoid lymphocytes on PBF examination. Conclusion: Raised hematocrit, Leucopenia with relative lymphocytosis, thrombocytopenia and presence of plasmacytoid lymphocytes ( >10\% of total lymphocytes) was consistent finding and gives an important diagnostic clue for dengue.
\end{abstract}

Keywords: Dengue, plasmacytoid lymphocytes, atypical lympocytes, monocytoid lymphocytes, lymphocytosis

\section{Introduction}

Dengue is one of the most important mosquito-borne viral disease affecting humans. Dengue virus infection is endemic in many parts of the world and widespread in tropical countries of Asia including India. The WHO estimates that 50 to 150 million cases of dengue infection occur each year [1],[2]. More than three lakh cases of Dengue Hemorrhagic Fever are diagnosed each year. Dengue causes a fatality of 24000 deaths per year.

Dengue fever is caused by single stranded RNA virus of Flaviviridae family with four serotypes 1,2,3,4. The most common epidemic vector of dengue is female Aedes Aegypti mosquito [3],[4] easily identified by white bands or scale pattern on its legs and thorax. The clinical manifestation of symptomatic dengue includes fever, headache, muscle and joint pain, nausea and vomiting, rash and hemorrhagic manifestations. These are divided in four clinical syndromes:

1) Undifferentiated Fever

2) Classis Dengue fever

3) Dengue hemorrhagic fever

4) Dengue shock syndrome

Clinical diagnosis of dengue remains a challenge for physician in areas where it could not be differentiated from other febrile illnesses like malaria, typhoid and leptospirosis etc[5]. So early diagnosis of dengue is important for provision of specific care which ensures marked reduction in the morbidity of disease. Complete blood count and PBF examination is an important part of initial workup. Thrombocytopenia and Presence of Plasmacytoid lymphocyte on smear is a diagnostic clue [6]. With our current state of art automated CBC and Differential, we are missing the atypical lymphocytes reporting, which are helpful in diagnosing differential disease state.

The aim of this study was to look at the consistent morphological features seen in PBF that can support the diagnosis. The full blood count parameters were also assessed in this study.

\section{Materials and Method}

This was a cross sectional study which was carried out on a series of patients attending at MG Hospital, Jodhpur between sept 2015 to Nov 2015 with chief complaint of high grade fever, bodyache, joint pain and lethargy. Complete Blood Count (CBC) and PBF examination were first performed for every patient's venous sample collected in EDTA Vial. After analysing the sample, whose sample showing leucopenia with relative lymphocytosis, Thrombocytopenia and presence of Plasmacytoid Lymphocytes on PBF were further tested by Rapid card test for NS1 Ag(0-5 days of fever) or Ig G and IgM antibody for dengue( more than 5 days of illness).

The patients were divided in two groups. Patients who came positive on NS1 Ag or IgM antibody for dengue (By rapid card method, as ELISA facility not available everywhere) were put into Dengue or test group, and other patients presenting with similar complaints who were dengue negative but either malaria or widal positive and two patients who were both malaria and widal negative considered to be non specific viral fevers were put into control group.

Complete Blood Count was carried out on automated cell counters i.e. Sysmex XS 800 i. The blood smears were stained with Giemsa stain [15]-[17]. 


\section{International Journal of Science and Research (IJSR) \\ ISSN (Online): 2319-7064 \\ Index Copernicus Value (2013): 6.14 | Impact Factor (2014): 5.611}

Differential counts were done manually also on all smears of both groups and atypical lymphocytes, both monocytoid and plasmacytoid lymphocytes were counted separately from mature lymphocytes. Low platelet counts given by cell counter were confirmed by peripheral blood smears.

Typical plasmacytoid lymphocytes are defined as large lymphocyte with moderate nuclear cytoplasmic ratio and intensely basophilic cytoplasm with eccentrically placed nucleus. The nuclear chromatin pattern resembled more or less to mature lymphocytes. Leucopenia was defined as Total Leucocyte count less than 4000/ul and Thrombocytopenia defined as platelet count less than $1,00,000 /$ ul.

\section{Results}

Total 150 patients were studied. Among 150, the 50 patients were in dengue group and 100 patients were kept in control group (Dengue negative group). Dengue negative group includes 70 cases of malaria, 28 cases of typhoid and 2 cases of nonspecific viral fever (malaria and widal both negative)
Table 1: Hematological findings among study group and control group

\begin{tabular}{|c|c|c|c|c|}
\hline Variable & \multicolumn{2}{|c|}{ Study Group } & \multicolumn{2}{c|}{ Control Group } \\
\hline \multirow{3}{*}{ Hemoglobin } & Range & Average & Range & Average \\
\cline { 2 - 5 } & $\begin{array}{c}7.5 \mathrm{gm} \%- \\
17.2 \mathrm{gm} \%\end{array}$ & $\begin{array}{c}14.3 \\
\text { gm\% }\end{array}$ & $\begin{array}{c}8.1 \mathrm{gm} \%- \\
16.6 \mathrm{gm} \%\end{array}$ & $11.2 \mathrm{gm} \%$ \\
\hline Hematocrit & $\begin{array}{c}19.2 \%- \\
52.4 \%\end{array}$ & $41.0 \%$ & $\begin{array}{c}24.2 \%- \\
51.2 \%\end{array}$ & $32.0 \%$ \\
\hline Total Leucocyte count & $1410 /$ & $5180 /$ & $2000 / \mathrm{cmm}-$ & $6200 / \mathrm{cmm}$ \\
& $\mathrm{cmm}-$ & $\mathrm{cmm}$ & $9700 / \mathrm{cmm}$ & \\
& 11520 & & & \\
$/ \mathrm{cmm}$ & & & \\
\hline Platelets count & $6000 / \mathrm{ul}-$ & $59500 / \mathrm{ul}$ & $34000 / \mathrm{ul}-$ & $86000 / \mathrm{ul}$ \\
& $175000 / \mathrm{ul}$ & & $267000 / \mathrm{ul}$ & \\
\hline $\begin{array}{c}\text { Lymphocytes(including } \\
\text { plasmacytoid) of TLC }\end{array}$ & $36 \%-75 \%$ & $58 \%$ & $2.42 \%-40 \%$ & $21.5 \%$ \\
\hline $\begin{array}{c}\text { Plasmacytoid } \\
\text { lymphocytes/sum of } \\
\text { mature and } \\
\text { plasmacytoid } \\
\text { lymphocytes }\end{array}$ & $12.1 \%-$ & $21.76 \%$ & $2.9 \%-$ & $6.42 \%$ \\
& $64.7 \%$ & & $10.8 \%$ & \\
\hline
\end{tabular}

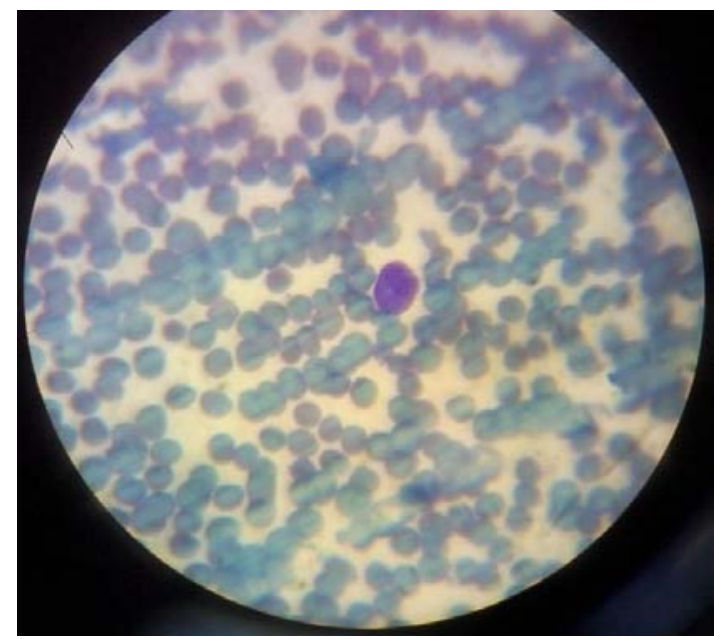

Picture 1: micro photograph showing a plasmacytoid lymphocyte (Gimsa; X 45)

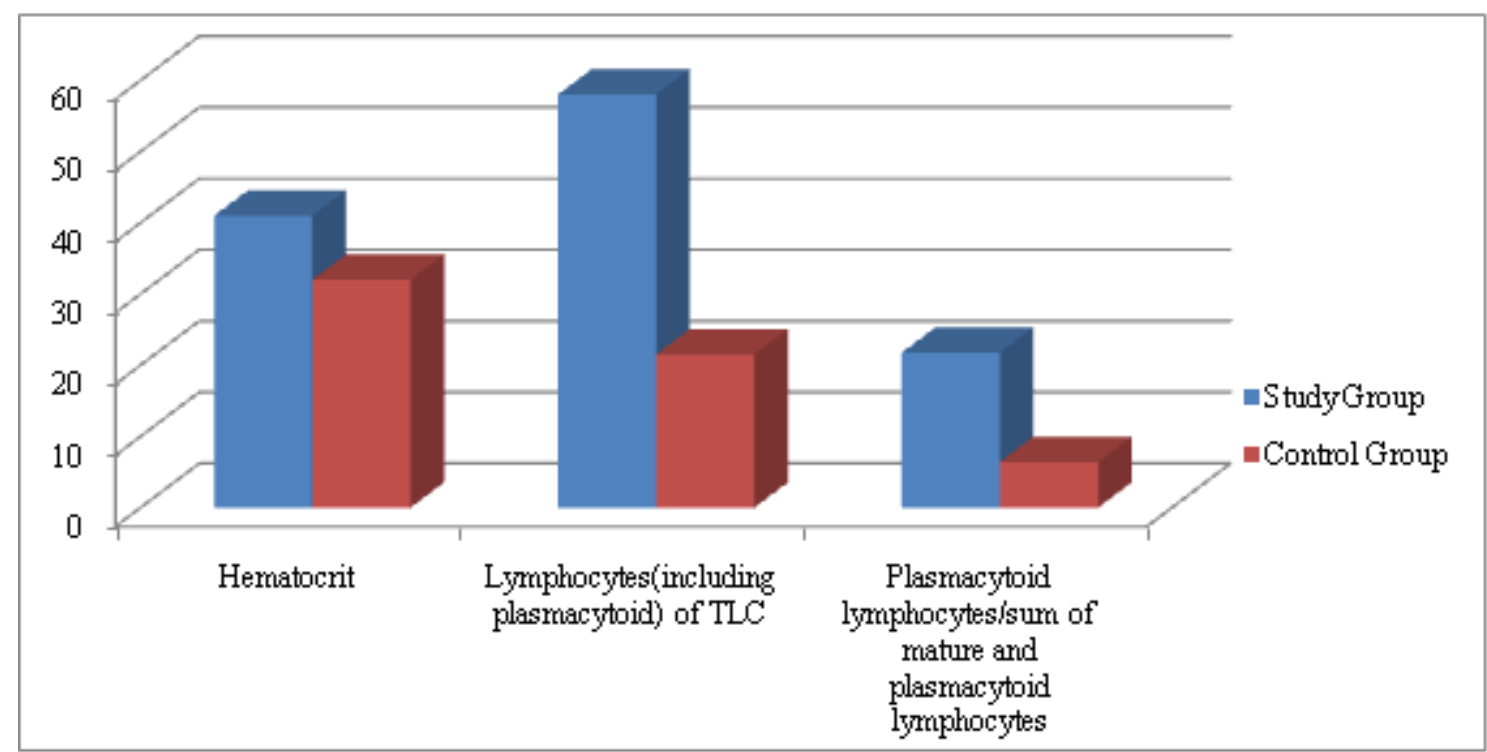

Chart 1: Depicting hematocrit, Lymphocytes and plasmacytoid lymphocytes in test and control group. 


\section{International Journal of Science and Research (IJSR) \\ ISSN (Online): 2319-7064 \\ Index Copernicus Value (2013): 6.14 | Impact Factor (2014): 5.611}

Table 2: Characteristics of Dengue with Plasmacytoid lymphocytes among study group

\begin{tabular}{|c|c|c|c|}
\hline $\begin{array}{c}\text { Lympho } \\
\text { Dengue }\end{array}$ & $\begin{array}{c}\text { Plasmacytoid } \\
\text { Lymphocytes } \\
\text { present }\end{array}$ & $\begin{array}{c}\text { Plasmacytoid } \\
\text { Lymphocytes } \\
\text { absent }\end{array}$ & Total \\
\hline Dengue Positive & 50 & 0 & 50 \\
\hline Dengue Negative & 22 & 78 & 100 \\
\hline Total & 72 & 78 & 150 \\
\hline
\end{tabular}

Table 3: Platelets count among Dengue and Non Dengue group

\begin{tabular}{|c|c|c|c|}
\hline Thromocytopenia & $\begin{array}{c}\text { Thrombocytopenia } \\
\text { present } \\
\text { Platelets }<1 \text { lac }\end{array}$ & $\begin{array}{c}\text { Thrombocytopenia } \\
\text { absent } \\
\text { Platelets }>1 \text { lac }\end{array}$ & \\
\hline Dengue & $37(74 \%)$ & 13 & 50 \\
\hline Dengue Positive & $62(62 \%)$ & 38 & 100 \\
\hline Dengue Negative & 99 & 51 & 150 \\
\hline Total & \multicolumn{2}{|}{} \\
\hline
\end{tabular}

In Dengue positive group, relative lymphocytosis was observed in 40 ( $80 \%$ ) patients and in dengue negative group $18(18 \%)$ were found with relative lymphocytosis. Among Lymphocytes, In dengue positive group 21.76\% (Avg) were plasmacytoid lymphocytes and in control group they were only $1.41 \%(A v g)$. In dengue positive group atypical lymphocytes belonged to plasmacytoid morphology while in control group they belonged to monocytoid morphology mainly in typhoid and malaria cases and in non specific viral cases their percentage was much less.

In dengue positive group palsmacytoid lymphocytes( of total lymphocytes) ranged from $12.1 \%$ to $64.7 \%$ (18) with a mean of $21.76 \%$. Standard deviation for dengue positive group was calculated as 10.73 and mean deviation was 7.712. In dengue negative group mean of plasmacytoid lymphocytes( of total lymphocytes) was 1.414 and standard deviation was calculated as 2.54 .

Standard error between means of dengue positive group and control group was 1.54, but the actual differences between means of those were 20.346. Actual difference between means was far greater than twice (3.08) of standard error between means. So this shows a significant difference of plasmactoid lymphocytes between dengue and control group.

We also applied chi-square test on our data. In published probability table, with 1 degree of freedom, the value of chisquare for probability of 0.001 is 10.83 . Since the observed value (81.25) is far greater than table value (10.83), we concluded that the null hypothesis is false and presence of plasmacytoid lymphocytes (19) in dengue positive group is significant $(\mathrm{P}<0.001)$.

\section{Discussion}

A range of findings in $\mathrm{PBF}$ are seen mostly during viral infection. Presence of Haemoconcentration, Leucopenia, Thrombocytopenia and plasmacytoid lymphocytes are well known findings in Dengue viral infection.

Leucopenia was observed in $26 \%$ of patients by Ratagiri et al [8], while leucopenia in our study was observed in $32 \%$ patients associated with rise in percentage of lymphocytes. This finding is parallel to marrow suppression during acute phase [9],[10]. Relative lymphocytosis along with plasmacytoid lymphocytes is response to viral antigen due to recognition followed by transformation to plasmacytoid lymphocytes to control the spread of dengue virus infected cells [11].

\section{Thrombocytopenia}

(Platelet count $<1 \mathrm{lac} / \mathrm{cmm}$ ) was seen in $74 \%$ of patients. The platelet count was evaluated by Sysmex XS 800i and in Giemsa stained PBF. The counter gives false low reading when large platelets are present. Such platelet counts were corrected by PBF. Dietz et al reported thrombocytopenia in $34 \%$ of cases [12]. Thrombocytopenia is thought to be due to suppression of bone marrow observed in acute phase of dengue [9]. Other explanation includes direct infection of megakaryocytes, presence of antibodies against platelets and release of high levels of platelet activating factor by monocytes[13].

Hemorrhagic manifestations are very common with severe thrombocytopenia and severity of hemorrhagic tendancy correlates with platelets count [14].

\section{Conclusion}

Through the above study, we can conclude that raised hematocrit, leucopenia with relative lymphocytosis, thrombocytopenia along with plasmacytoid lymphocytes is consistent finding in dengue fever and gives important diagnostic clue.

In developing countries like India, where resources are limited, these types of diagnostic clue can save many resources for real needful persons. This can also prevent unnecessary anti-malarial drugs exposure to patients and avoid development of anti-malarial drug resistance, as dengue patients do not need anti-malarial and other antibiotics therapy as there is no specific drug for dengue apart from supportive care.

\section{References}

[1] World Health Organisation. "Dengue Hemorrhagic Fever: Diagnosis, treatment, prevention and control". $2^{\text {nd }}$ edn. Geneva: WHO.1997.

[2] Gubler DJ. "“'Dengue Hemorrhagic Fever”. Clin Microbiol Rev.1998; 11: 480-96.

[3] Gubler DJ, Meltzer M. "Impact of Dengue and Dengue hemorrhagic fever on developing world". Adv virus research 1999; 53:35-70.

[4] Platt KB, Linthicum KJ, Myint KS, Innis BL, Lerdthurnee K, Vaughn DW. "Impact of dengue virus infection on feeding behaviour of Aedes aegypti”. Am J Trop Med Hyg 1997; 57: 119-25.

[5] World Health Organisation "World Health Organisation and the special programme for research and training in tropical disease (2009) Dengue: guidelines for diagnosis, treatment, prevention and control" 2009.

[6] Gomber S, Ramchandran VG, Kumar S, Agarwal KN, Gupta P et al. " Hematological observation as diagnostic 
marker in dengue hemorrhagic fever- a reappraisal" Indian Pediatr.2002; 38(5): 477-81.

[7] Bell A, Sallah S. "The morphology of Human blood cells" $7^{\text {th }}$ edn.2005; Abott US.

[8] Rategiri H, Shepur TA, Wari PK, Chavan SC." Clinical profile and outcome of dengue fever cases" Ind J of Pediatrics 2005; 72:705-6.

[9] La Russa VF, Innis BL. "Mechanism of dengue virus induced bone marrow suppression" Baillieres Clin Hematol 1995; 8 (1): 249-70.

[10] Quereshi JA, Notta NJ, Salabuddin N, Zaman V, Khan JA." An epidemic of dengue fever in Karachi: associated clinical manifestations" J Pak Med Assoc. 1997; 47:178-81.

[11] Carlos CC, Oishi K, Cinco MT, Mapua CA, Inoue S, Cruz DJ et al “ Comparision of clinical features and haematological abnormalities between dengue fever and dengue hemorrhagic fever among children in Philippines" Am J Trp Med Hyg 2005, 73 (2); 435-40.

[12] Dietz V, Gubler DJ, Ortiz S et al" The 1986 dengue and dengue hemorrhagic fever epidemic in Puerto Rico: epidemiologic and clinical observation" PR Health Science J; 1996; 15:201-10.

[13] Ostronoff M, Ostronoff F, Florencio R, Florencio M, Domingues MC, Calixto $\mathrm{R}$ et al “ Serious thrombocytopenia due to dengue hemorrhagic fever treated with high doses of immunoglobulins. Clinical Inf Dis, 2003; 36: 1623-24.

[14] Natasha Ali, Mohammad Usman, Naveen Syed, Mohammad khurshid " Hematologic manifestations and utility of haematological parameters in dengue fever: a tertiary care centre experience at Karachi” Scandinavian Journal of Infectious Disease 2007; 39(1112): 1025-28.

[15] Chadwick D, Arch B, Wilder-Smith A, Paton N. Distinguishing dengue fever from other infections on the basis of simple clinical and laboratory features: application of logistic regression analysis. J Clin Virol 2006;35:14753.

[16] KalayanaroojS, Vaughn DW, Nimmannitya S, Green S, Suntyakorn $\mathrm{N}$ et al. Early clinical and laboratory indicators of acute dengue illness.J Infect Dis 1997; 176(2):313-21.

[17] Lin SF, Liu HW, Chang CS, Yen JH, Chen TP. Hematological aspects of dengue fever. Gaoxiong Yi Xue

$\mathrm{Za}$

Zhi. 1989; 5(1):12-16.

[18]John M Gawoski, Winnie W ooi. Dengue fever mimicking plasma cell leukemia. Archives of pathology and Laboratory Medicine 2003; 127(8): 1026-7.

[19] Thisyakorn U, Nimmannitya S, Ningsanond V, Soogarun S. Atypical lymphocyte in dengue hemorrhagic fever. Its value in diagnosis. Southeast Asian j trop Med Pub Hlth. 1984;15:32-6. 